\title{
Palatability for goat of some Mediterranean shrubs. Comparison between browsing time and cafeteria technique
}

\author{
A Nefzaoui 1, H Ben Salem 1, H Abdouli 2, H Ferchichi 1 \\ IINRA de Tunisie, Laboratoire de Nutrition Animale, rue Hédi Karray, 2049 Ariana ; 2 ESA Mateur. \\ Laboratoire de Nutrition Animale, 7049 Mateur, Tunisia
}

This investigation was carried out in order to compare two methods for estimating palatability, the browsing time and the cafeteria type technique. The trials were held in a semi arid range land of Central Tunisia. Alpine $x$ local breed goats were used for experiments.

The experimental range land covers an area of approximately 20 ha. In addition to herbaceous species, 7 dominant woody species are present at different covering rates. Artemisia campestris (13.7\%), Artemisia herba alba $(0.8 \%)$, Cistus libanotus $(6.1 \%)$, Cistus salvifolus $(3.8 \%)$, Globularia alypum $(7.2 \%)$, Pistacia lentiscus $(5.1 \%)$ and Rosmarinus officinalis $(5.9 \%)$.

Three Alpine $x$ local breed goats were identified with 3 different colours and were allowed to browse with their 200-head flock on the range land during three consecutive days of each month. During this period, animals were released daily on pasture from 09.00 to 16.00 hours. The time spent by each goat consuming a particular plant specie was recorded during a 30 minute period (morning and afternoon), according to a $3 \times 3$ Latin square design. At the barn, each animal received a supplement of $400 \mathrm{~g}$ of barley grain and $200 \mathrm{~g}$ of barley hay. Palatability of shrubs measured in the above trial was also determined on stall fed goats during the same study period. From the same flock, we chose nine Alpine $x$ local breed goats for this study. Animals were put into three homogenous groups and were confined by group in an enclosure equipped with 8 troughs. Before starting the experiment, animals were adapted, during one week, to experimental conditions. 15-day periods were retained to measure, once monthly, the palatability of shrubs. The freshly-cut shrubs were offered ad libitum simultaneously and supplemented with $400 \mathrm{~g}$ barley grain per head. Order of distribution of shrubs in troughs was changed daily to avoid animals "habit-reflex". Amounts of offered feeds and refusals corresponding to each group were recorded daily and sampled for subsequent chemical analysis.

Browsing time has a wide variation among shrubs and months. Goats spend an average of $60 \%$ of the grazing time for woody species. Such a trend, when compared to that obtained with the cafeteria technique, where goats showed a rather constant preference for shrubs, allowed the conclusion that free browsing method is different from the cafeteria technique. Overall, regression analyses of palatability results showed no significant correlations between palatability measured by free browsing time and cafeteria techniques. Animals confined for long periods become accustomed to stall conditions and fix their choice for available feeds independently of plant characteristic variations. At the contrary of free browsing technique, where there is no significant relationship between palatability and fodder characteristics, we find palatability measured by the cafeteria technique significantly correlated to fibre contents of shrubs and especially to the rapidly degradable dry matter fraction of shrubs (a) in the rumen $\left(I 15 D=0.545-0.007 a ; r^{2}=0.64\right)$.

Thus, since it is not proven that the browsing time is well related to the amounts consumed, the choice of the accurate method for palatability determination remains a conflicting problem. 